\title{
The Role of Magnetic Resonance Imaging in the Management of Esophageal Cancer
}

\author{
Anna Pellat ${ }^{1,2}$, Anthony Dohan 2,3 ${ }^{(D}$, Philippe Soyer ${ }^{2,3}$, Julie Veziant ${ }^{2,4}$, Romain Coriat ${ }^{1,2}$ (D) \\ and Maximilien Barret $1,2, *$ (D)
}

1 Department of Gastroenterology and Digestive Oncology, Hôpital Cochin, AP-HP, 27 rue du Faubourg Saint Jacques, 75014 Paris, France; anna.pellat@aphp.fr (A.P.); romain.coriat@aphp.fr (R.C.)

2 Université de Paris, 75006 Paris, France; anthony.dohan@aphp.fr (A.D.); philippe.soyer@aphp.fr (P.S.); julie.veziant@aphp.fr (J.V.)

3 Department of Radiology, Hôpital Cochin, AP-HP, 27 rue du Faubourg Saint Jacques, 75014 Paris, France

4 Department of Digestive Surgery, Hôpital Cochin, AP-HP, 27 rue du Faubourg Saint Jacques, 75014 Paris, France

* Correspondence: maximilien.barret@aphp.fr

check for updates

Citation: Pellat, A.; Dohan, A.; Soyer, P.; Veziant, J.; Coriat, R.; Barret, M. The Role of Magnetic Resonance Imaging in the Management of Esophageal Cancer. Cancers 2022, 14, 1141. https://doi.org/10.3390/ cancers14051141

Academic Editor: Bas P.L. Wijnhoven

Received: 3 January 2022

Accepted: 18 February 2022

Published: 23 February 2022

Publisher's Note: MDPI stays neutral with regard to jurisdictional claims in published maps and institutional affiliations.

Copyright: (C) 2022 by the authors. Licensee MDPI, Basel, Switzerland. This article is an open access article distributed under the terms and conditions of the Creative Commons Attribution (CC BY) license (https:// creativecommons.org/licenses/by/ $4.0 /)$.
Simple Summary: Esophageal cancer (EC) is the eighth most frequent cancer worldwide, with a poor prognosis. Current imaging modalities for staging and follow-up mainly include computed tomography (CT), positron emission tomography (PET)/CT, and endoscopic ultrasound. Magnetic resonance imaging (MRI), which is a non-irradiating and non-invasive modality, can provide identification of the esophageal wall and esophagogastric junction. MRI has shown encouraging capabilities in regional and local staging of EC as well as in the assessment of treatment response to therapy. Technical refinements in MRI technique and sequences overtime have contributed to its increasing diagnostic performance as well as its generalizability. MRI could become a routine imaging technique for EC management in the future, alone or in combination with other modalities.

\begin{abstract}
Esophageal cancer (EC) is the eighth more frequent cancer worldwide, with a poor prognosis. Initial staging is critical to decide on the best individual treatment approach. Current modalities for the assessment of EC are irradiating techniques, such as computed tomography (CT) and positron emission tomography/CT, or invasive techniques, such as digestive endoscopy and endoscopic ultrasound. Magnetic resonance imaging (MRI) is a non-invasive and non-irradiating imaging technique that provides high degrees of soft tissue contrast, with good depiction of the esophageal wall and the esophagogastric junction. Various sequences of MRI have shown good performance in initial tumor and lymph node staging in EC. Diffusion-weighted MRI has also demonstrated capabilities in the evaluation of tumor response to chemoradiotherapy. To date, there is not enough data to consider whole body MRI as a routine investigation for the detection of initial metastases or for prediction of distant recurrence. This narrative review summarizes the current knowledge on MRI for the management of EC.
\end{abstract}

Keywords: esophageal cancer; magnetic resonance imaging; staging

\section{Introduction}

According to the global cancer observatory, esophageal cancer (EC) is currently the eighth most common cancer worldwide and the sixth most common cause of death by cancer (https: / /gco.iarc.fr/, accessed on 17 December 2021). About 600,000 cases were diagnosed in 2020, with more than 540,000 deaths. Both incidence and mortality rates vary greatly across countries [1]. Until recently, surgery and the combination of chemoradiotherapy have been the main treatments for EC in the localized setting. The recent CheckMate 577 trial has shown improved disease-free survival for patients treated with nivolumab, an immune checkpoint inhibitor, in the adjuvant setting of operated EC after neoadjuvant 
chemoradiotherapy [2]. In the metastatic setting, chemotherapy and immune checkpoint inhibitors are the main available treatments $[3,4]$.

Upon diagnosis, clinical and radiological staging is crucial to propose the optimal treatment strategy to patients. Several imaging techniques, including computed tomography (CT), positron emission tomography (PET)/CT, endoscopic ultrasound (EUS), as well as esophagogastroduodenoscopy, are recommended by European guidelines in the management of EC [5,6]. A preoperative CT classification has been proposed by Bosset et al. (cTNM) [7]. The TNM staging system, provided by the American Joint Committee on Cancer (AJCC) and the International Union Against Cancer (UICC), is used for pathologic tumor classification of the disease [8]. Contrary to other modalities, magnetic resonance imaging (MRI) is a non-irradiating and non-invasive technique. It also provides excellent soft-tissue contrast. It is not currently a routine examination for the management of EC because of its relatively low availability and its technical limitations. Nevertheless, it seems a promising technique for tumoral staging, delineation of target volumes before chemoradiotherapy, response to treatment and prediction of recurrence. Improvement of MRI modalities over the years, and the development of a larger choice of sequences, have contributed to enhancing MRI performance in EC.

The purpose of this narrative review was to sum up the current evidence on the role of MRI in the management of EC.

\section{MRI Modalities for the Esophagus}

\subsection{Major Technical Developments in MRI of the Esophagus Overtime}

Measurements and description of the normal esophagus in the sagittal view were first assessed in 78 patients using electrocardiogram (ECG)-gated MRI. In 2004, Manabe et al. compared T1-weighted ultrafast gradient echo (TFE) MRI and T1-weighted fast field echo (FFE) MRI in 20 healthy volunteers, with the aim to delineate the esophageal passage under dynamic conditions [9]: The fast field echo images proved superior in terms of signal to noise ratio and overall quality [9]. The use of an external surface coil and cardiac gating with T2-weighted fast spin-echo (FSE) sequences was shown in 2006 to further improve the signal of the quality of esophageal MRI, and the speed of acquisition [10]. Later, an ex vivo study using high field MRI with a similar protocol helped precisely define the MRI anatomy of the posterior mediastinum [11]. Similarly, in a study on 33 operated patients with EC, preoperative high-resolution T2-weighted FSE sequence provided detailed images and comparison with histology findings showed good correlation between the degree of esophageal wall infiltration and pathological T-staging [12]. Furthermore, ultra-highresolution T2-weighted MRI at 7.0-T provided clear definition of the esophageal wall and excellent accuracy for the T staging [13]. In 2017, pre-treatment motion-triggered MRI was used to improve the description of the periesophageal tissue [14].

Dynamic MRI of the esophagus, using oral administration of various contrast agents, has been proposed to assess the esophageal peristalsis on sagittal images [15]. Gadopentetate dimeglumine mixed with barium [16], ferric ammonium citrate-cellulose paste [17], buttermilk spiked with gadolinium chelate [15], concentrated pineapple juice mixed with potato starch [18] were tested with satisfactory results, allowing to describe the esophagus in the sagittal plane over a mean of $16 \mathrm{~cm}$, and define normal values for the esophageal transit time $[19,20]$. Noticeably, the latter intraluminal agent provided a similar image quality to those obtained with paramagnetic contrast agents.

\subsection{How We Do It in Our Center}

In our center, we obtain T1-weighted images in the coronal and axial planes before and after intravenous administration of a gadolinium chelate; then T2-weighted single shot spine echo sequences in the axial and coronal plane, and dynamic kinematic acquisition of steady-states sequences are obtained in the oblique plane, parallel to the esophagogastric junction. Patients are asked to swallow water through a straw during the dynamic acquisition phase. This is repeated several times in order to visualize the esophageal contractions. 
The sequences parameters are presented in the Table 1. The correct placement of sagittal oblique kinematic sequences is of paramount importance to visualize the esophagus and the esophagogastric junction. Indeed, the presence of the heart in the acquisition box will lead to motion artifacts. Morphological signs are analyzed on T2 weighed images and steady state cine sequences.

We present in Figures 1 and 2 the results of different modalities used for initial staging of EC in two different patients.

Table 1. How we do it in our center: different magnetic resonance imaging sequence parameters at $1.5 \mathrm{~T}$ (Siemens Aera, vb20a).

\begin{tabular}{ccccc}
\hline Sequence Parameter & T2-Single Shot TSE & Steady States & $\begin{array}{c}\text { Diffusion } \\
\text { (EPI) }\end{array}$ & $\begin{array}{c}\text { T1-Weighted before and } \\
\text { after Gadolinium Chelate }\end{array}$ \\
\hline Plane & Axial and coronal & Oblique & Axial & Axial and coronal \\
\hline TE/TR $(\mathrm{ms})$ & $93 / 100$ & $1.71 / 433$ & $80 / 7900$ & $2.19 / 4.85$ \\
\hline Flip angle $\left({ }^{\circ}\right)$ & 150 & 60 & 90 & 10 \\
\hline FOV $(\mathrm{mm})$ & $450 \times 450$ & $360 \times 360$ & $20 \times 380$ & $380 \times 308$ \\
\hline Matrix size & $384 \times 269$ & $256 \times 256$ & 7 & 200 \\
\hline Slice thickness $(\mathrm{mm})$ & 6 & 10 & $1.1 \times 1.1 \times 7$ & $1.2 \times 1.2 \times 2$ \\
\hline Voxel size $\left(\mathrm{mm}^{3}\right)$ & $1.2 \times 1.2 \times 6$ & $0.7 \times 0.7 \times 10$ & 40 & 80 \\
\hline Number of slices & 23 & 1 & 20 & 20 \\
\hline Inter-slices gap $(\%)$ & 30 & $\mathrm{NA}$ & \\
\hline
\end{tabular}

TSE: turbo spin echo, EPI: echo planar imaging, TE: echo time, TR: repetition time, FOV: field of view, NA: not applicable.

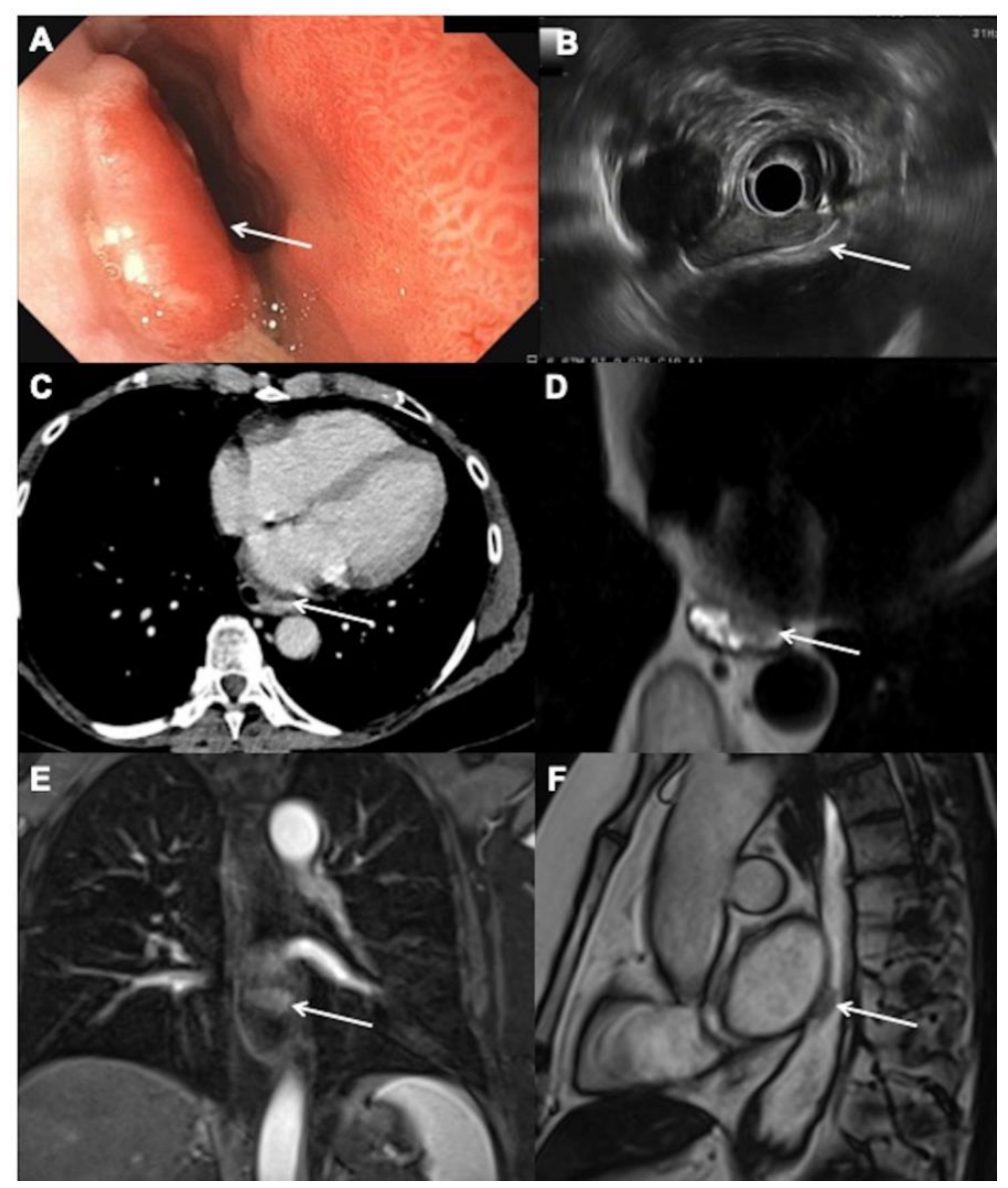

Figure 1. Initial staging for a 66-year-old woman with T2N0M0 esophageal adenocarcinoma: (A) endoscopic view of an elevated neoplastic lesion arising on a Barrett's esophagus on the left posterior 
side of the esophagus, $34 \mathrm{~cm}$ from the dental arch (arrow). (B) Endoscopic ultrasound showing the hypoechoic, well-limited neoplastic lesion in close contact with the muscularis propria without regional lymph nodes (arrow). (C) Contrast-enhanced computed tomography image obtained at $70 \mathrm{~s}$ after intravenous administration of iodinated contrast material and without oral contract material in the axial plane shows irregular esophagus (arrow) but no definite lesion. (D) Axial T2-weighted single shot magnetic resonance (MR) images. after oral administration of water show a low signal irregular anterior lesion (arrow). (E) Coronal contrast-enhanced T1 weighted images confirm the lesion that demonstrates an early contrast uptake (arrow). (F) Sagittal steady-state MR images confirm the low signal lesion (arrow) and allow to precisely see its location.

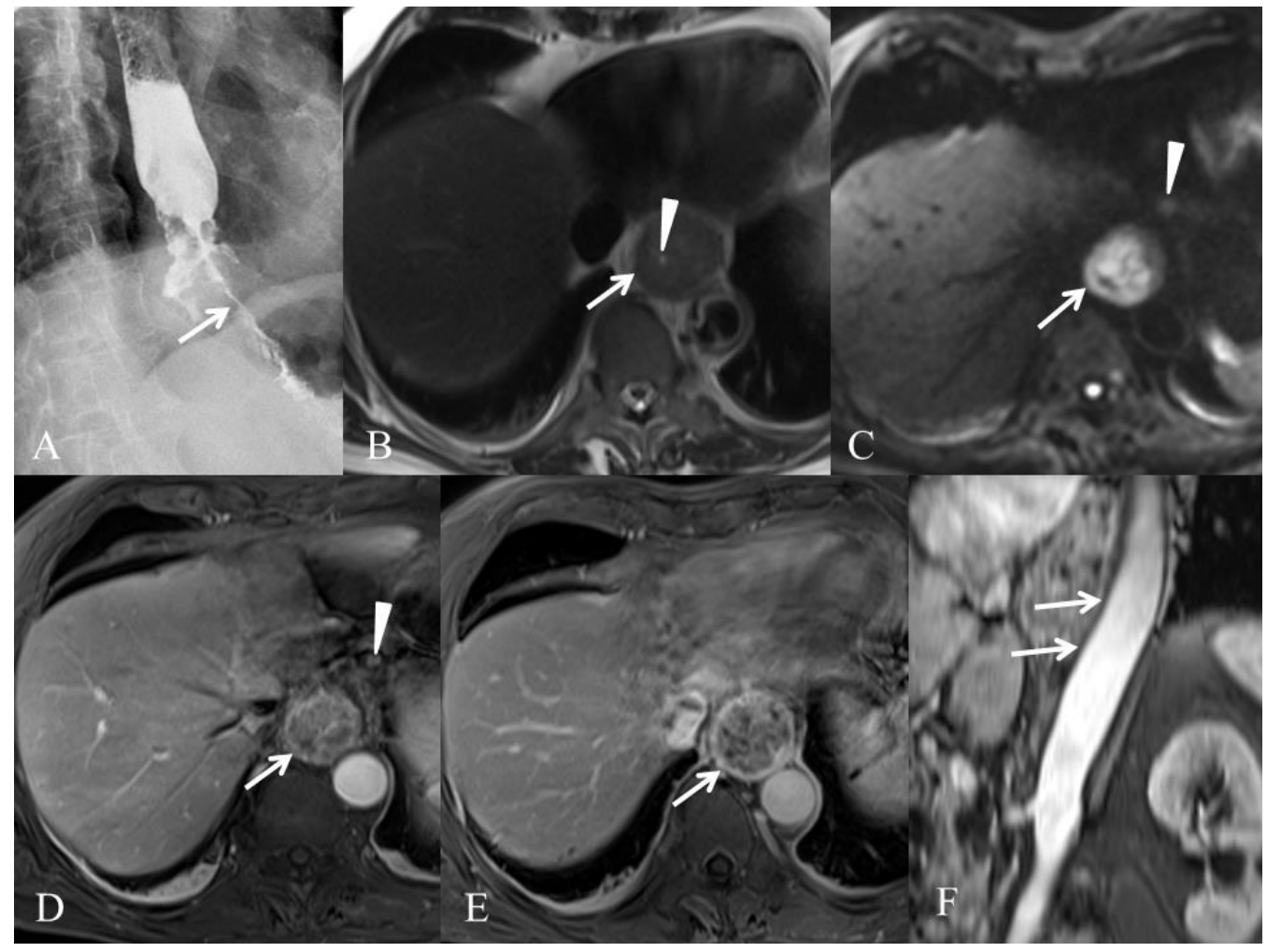

Figure 2. Initial staging for a 77-year-old man with T3N1M0 esophageal adenocarcinoma. (A) Esophagram shows esophageal tumor of the lower third of the esophagus responsible for marked luminal narrowing (arrow). (B) T2-weighted HASTE MR image in the axial plane shows esophageal tumor (arrow) with luminal narrowing (arrowhead). (C) Diffusion-weighted MR image in the axial plane obtained with high $b$ value $\left(b=800 \mathrm{~s} / \mathrm{mm}^{2}\right)$ shows restricted diffusion (arrow) consistent with malignant esophageal tumor. Additional hyperintense lymph node is present (arrowhead). (D) T1-weighted VIBE image in the axial plane obtained $30 \mathrm{~s}$ after intravenous administration of a gadolinium-based contrast agent (gadoterate meglumine, Dotarem ${ }^{\circledR}$, Guerbet, Villepinte, France) shows heterogeneous esophageal tumor (arrow) and enhancing lymph node (arrowhead). (E) T1-weighted VIBE image in the axial plane obtained $60 \mathrm{~s}$ after intravenous administration of a gadolinium-based contrast agent (gadoterate meglumine, Dotarem ${ }^{\circledR}$, Guerbet) shows that the tumor is well delineated without spreading outside the adventitia (arrow). (F) MR angiography image in the oblique plane shows intact interface (arrows) between esophageal tumor and aorta.

\section{MRI and Esophageal Cancer (EC) Diagnosis and Staging}

\subsection{Initial Tumor $(T)$ Staging}

One of the major challenges in EC is the evaluation of local staging in order to choose the best treatment approach. For low stage EC, the optimal treatment between upfront 
surgery or administration of neoadjuvant therapy is still unclear and will be influenced by robust staging.

Tumor (T) staging is often done with EUS. In 2008, a meta-analysis on preoperative EC including 49 studies found pooled sensitivities ranging from 81.6 to $92.4 \%$ for differentiation of different T-stages, with a better performance in advanced (T4) disease [21]. Pooled specificities were $99.4 \%$ and $97.4 \%$ for $\mathrm{T} 1$ and $\mathrm{T} 4$ cancers, respectively [21]. In a more recent meta-analysis on preoperative ESCC, the overall accuracy of EUS for T-staging was 79\% (95\% CI: 88-94) [19]. EUS is superior to CT for evaluation of T-staging since CT cannot distinguish the different histological layers [20,22,23]. CT can be reliable when it comes to determining resectability by excluding high T-stages tumors $[24,25] .{ }^{18} \mathrm{~F}$ fluorodeoxyglucose $\left({ }^{18} \mathrm{~F}-\mathrm{FDG}\right) \mathrm{PET} / \mathrm{CT}$ has a limited role for T-staging due to its low spatial resolution and is mainly useful for the diagnosis of distant metastases [24,26]. Although the local and regional staging accuracy of EUS is greater than those of CT and PET [27], EUS is invasive and operator dependent, and sometimes limited by tumor stenosis [28].

With this in mind, MRI seems a promising tool for the evaluation of T-staging in EC. Various in vitro studies found that MRI could clearly describe the different layers of the esophageal wall and had a high diagnostic accuracy for evaluating mural invasion $[29,30]$. Similar results were found in the ex-vivo setting with both high-resolution T2-weighted and diffusion-weighted MRI (DWI) [31-33], as well as in the in vivo setting [12,13]. Improvement of MRI modalities over the years has contributed in increasing the performance of MRI diagnosis and staging in EC [34,35]. Nevertheless, the heterogeneity of MRI modalities and sequences used in different studies limits the generalizability of currently available results. The T2-weighted FSE technique evaluated in 39 patients showed high accuracy in differentiating between $\mathrm{T} 2$ and $\mathrm{T} 3$ disease but with a tendency to overstage $\mathrm{T} 1$ tumors [12]. One trial evaluating the influence of two different volumetric interpolated breath-hold sequences (VIBE) on T-staging in EC, found that contrast-enhanced free-breathing radial VIBE was superior to breath-hold Cartesian VIBE, especially for T1 and T2 stage EC [36]. MR esophagography with water swallowing was evaluated in 30 patients with thoracic EC and 10 healthy volunteers [37]. By comparison with conventional MRI, it showed better results for assessing the tumor's length and exact localization, but lower accuracy for T-staging [38]. T2*-weighted imaging had good accuracy for the evaluation of T-staging in patients with ESCC, except for the differentiation between T0 and T1-stage tumors [39]. In a study by Wu et al., gross tumor volume (GTV) assessed on T2-weighted MRI, contrastenhanced T1-weighted and DWI in 60 patients with ESCC was associated with T-stage and the presence of lymph node metastases [40]. They also reported that GTV diagnosed on contrast-enhanced T1-weighted imaging better predicted T-stage [40]. Furthermore, one work suggested that whole-tumor histogram analysis of some pharmacokinetic parameters from dynamic contrast-enhanced (DCE)-MRI might be able to predict T-stage in ESCC [41]. In addition, MR angiography of the thorax in the same session provides very useful information about the invasiveness of the cancer in vessels, vascular anomalies, including arterial and venous status.

A recently published meta-analysis on 20 trials addressed the issue of MRI diagnostic performance for EC, including the question of precise T-staging [35]. With 11 trials published between 2009 and 2019 addressing the question of differentiation between T0 and T1 or more advanced disease, MRI had a pooled sensitivity of $92 \%$ (95\% CI: 82-96) and specificity of $67 \%$ (95\% CI: 51-81). The administration of neoadjuvant chemoradiotherapy did not significantly impact these results [35]. With 10 studies evaluating differentiation between T2 or lower disease and T3 or higher disease, MRI had a pooled sensitivity of $86 \%$ (95\% CI: 76-92) and a specificity of $86 \%$ (95\% CI; 75-93). Unfortunately, the authors did not address the specific question of the diagnostic value of MRI to differentiate between T0 or $\mathrm{T} 1$ tumor (amenable to endoscopic low morbidity resection) and $\geq \mathrm{T} 2$ tumors (requiring chemoradiotherapy and/or surgical resection). Overall, MRI had a good sensitivity for T-staging in EC. 
Evidence in favor of a high accuracy for T-staging by MRI in preoperative EC is growing, even if there is heterogeneity between available studies in terms of MRI sequences, study designs and histological subtypes of EC. MRI shows good sensitivity for low T-stages and good sensitivity and specificity for higher T-stages. In the close future, MRI alone, or in combination with other modalities, will probably be used in routine clinical practice for early T-staging of EC.

\subsection{Node (N) Staging}

Upon diagnosis, regional staging with evaluation of node $(\mathrm{N})$ staging is also crucial to evaluate prognosis and choose the optimal treatment approach. Not only is survival correlated with the T-stage, it is also clearly influenced by the N-stage [42]. Indeed, pathological evidence of lymph node metastases is a major prognostic factor in operated EC [37,42] with 5-year overall survival rates ranging between 70 and $92 \%$ in case of negative node involvement versus $18 \%$ to $47 \%$ for patients with positive lymph node involvement $[43,44]$. Furthermore, the lymph node ratio, which is the number of infiltrated lymph nodes divided by the total number of resected lymph nodes, is also an independent factor of survival for operated patients [45].

Currently, baseline regional lymph node involvement in EC is also preferably evaluated with EUS, followed by CT and ${ }^{18}$ F-FDG-PET/CT [24-26]. EUS can give access to fine needle aspiration (FNA) for histologic evaluation of regional lymph nodes (mediastinum and coeliac). In a 2008 meta-analysis, EUS showed a pooled sensitivity of $80 \%$ (95\% CI: 75-84) and pooled specificity of 70\% (95\% CI: 65-75) for N-staging [46]. Several studies have suggested that EUS-FNA had a greater accuracy than EUS alone for N-staging [47,48]. In the meta-analysis by Puli et al., pooled sensitivity of N-staging with EUS improved from 84.7 (95\% CI: 82.9-86.4) to 96.7\% (95\% CI: 92.4-98.9) with FNA [21]. In the meta-analysis by Van Vliet et al., both CT and ${ }^{18}$ F-FDG-PET/CT showed lower sensitivities for regional N-staging in EC, 50\% (95\% CI: 41-60) and 57\% (95\% CI: 43-70), respectively [46]. Regarding ${ }^{18}$ F-FDG-PET/CT, this could partly be explained by the difficulty in the distinction of lymph nodes adjacent to a highly avid primary tumor with a high standard uptake value.

Because of the previously described limitations of current techniques for N-staging, MRI has also been evaluated in this setting. Early studies using conventional MRI at 0.35-1.5 T without fast sequences reported sensitivities, specificities and diagnostic accuracies of $25-70 \%, 67-93 \%$ and 56-89\% respectively [49-52]. More recent studies with similar modalities support these findings and found similar sensitivities, specificities, and accuracies of 38-62\%, 68-85\% and 64-77\%, respectively $[53,54]$. Superparamagnetic iron oxide (SPIO), which is phagocytized by macrophages after intravenous administration, has enhanced the value of MRI in detecting lymph node metastases. Indeed, metastatic lymph nodes show a marked reduction in the uptake of SPIO due to a reduction in the number of phagocytes [55,56]. In a study on 16 patients by Nishimura et al., results were superior with an ultrasmall SPIO-enhanced MRI with sensitivity, specificity and accuracy of 100\%, 95\% and $96 \%$ respectively [54]. Limits to these results were the small number of patients included and the evaluation of differences between positive and negative lymph node groups rather than node-positive versus node-negative patients [54]. Later, a feasibility study on nine patients with EC and preoperative positive lymph node status, showed that ultrasmall SPIO-enhanced MRI could identify the majority of these suspected lymph node metastases [57]. In 2009, a study on 24 consecutive patients with EC showed that whole body DWI with background body signal suppression did not result in major diagnostic improvements for N-staging [58]. Recent evidence from a 2020 study on 76 patients suggested otherwise, with DWI showing higher sensitivity than ${ }^{18}$ F-FDG-PET/CT for the diagnosis of metastatic lymph node in ESCC [59]. In 35 patients with EC, ECG-triggered 1.5 T MRI with turbo spin-echo (TSE) and fast short tau inversion recovery (STIR) fat suppression yielded $81 \%$ sensitivity and $98 \%$ specificity for the diagnosis of lymph node involvement [60]. As mentioned previously, in the study by Wu et al., GTV assessed on T2-weighted imaging, contrast-enhanced T1-weighted and DWI in 60 patients with ESCC was associated with 
the presence of lymph node metastases [40]. Another study in 46 patients with EAC found similar results [61]. Recently, a radiomic signature with nine MRI features developed in a training cohort of 90 patients and confirmed in a validation cohort of 90 patients, showed good discrimination between metastatic and non-metastatic lymph nodes [62]. As for T-staging, one study suggested that whole-tumor histogram analysis of some pharmacokinetic parameters from dynamic contrast-enhanced MRI might be able to predict regional lymph node metastases in ESCC [41].

Performance of MRI for lymph node assessment was also evaluated in the recently published meta-analysis by Lee et al. [35]. With 10 trials published between 2007 and 2019 addressing the question of differentiation of N0 disease from N1 and more advanced disease, MRI had a pooled sensitivity and specificity of 71\% (95\% CI: $60-80)$ and $72 \%$ (95\% CI: 64-79) respectively [35].

Again, here, improvement of MRI modalities over the years has positively influenced its diagnostic performance for N-staging in EC. Even if recent evidence is also in favor of good sensitivity and specificity of MRI for N-staging, it remains difficult to draw firm conclusions due to the heterogeneity of MRI techniques used in the different existing studies and their small sample sizes.

\subsection{Metastases (M) Staging}

Assessment of distant metastases in EC is currently done with CT and ${ }^{18} \mathrm{~F}-\mathrm{FDG}-$ PET/CT. As previously mentioned, a 2004 meta-analysis evaluating the performance of ${ }^{18}$ F-FDG-PET/CT for the diagnosis of distant metastases found a pooled sensitivity and specificity of 67\% (95\% CI: 58-76) and 97\% (95\% CI: 90-100), respectively [26]. In the 2008 meta-analysis by Van Vliet at al., sensitivities and specificities for the diagnosis of distant metastases were 71\% (95\% CI: 62-79) and 93\% (95\% CI: 89-97) for ${ }^{18}$ F-FDG-PET/CT, 52\% (95\% CI: 33-71) and 91\% (95\% CI: 86-96) for CT [46]. In one study, restaging with ${ }^{18}$ F-FDG$\mathrm{PET} / \mathrm{CT}$ after neoadjuvant treatment of EC resulted in the diagnosis of metastases in $8 \%$ of patients, but also with false positive findings in $5 \%$ of patients [63]. Indeed, ${ }^{18} \mathrm{~F}-\mathrm{FDG}$ PET/CT shows several limitations that can affect its performance, such as the unspecific uptake of FDG, or the existence of low uptake tumors. Furthermore, ${ }^{18}$ F-FDG-PET $/ \mathrm{CT}$ is an expensive and irradiating technique. For all these reasons, the used of ${ }^{18}$ F-FDG-PET/CT in EC is limited to the initial workup of ESCC, and this imaging modality is rarely used for the dynamic monitoring of tumors, CT being the preferred investigation.

There is little data on the role of MRI in initial M-staging for EC. Two studies have evaluated the performance of whole-body MRI in that setting, one specifically in EC, and a second in a population with mixed gastrointestinal cancers including EC $[64,65]$. Compared with ${ }^{18}$ F-FDG-PET/CT, whole-body MRI had similar accuracy in detecting the primary tumor and lymph node metastases, and for excluding systemic metastatic disease [65]. In 49 patients with EC, both imaging modalities were able to identify distant metastases in two patients [65]. To date, there is however not enough data to recommend the routine use of whole-body MRI for M-staging in EC.

\subsection{Target Volume Delineation before Irradiation}

Accurate tumor delineation before radiotherapy, including accurate GTV, is important to ensure adequate target coverage while limiting toxicity for surrounding organs at risks. MRI is already used for tumor delineation before chemoradiotherapy in various tumor sites. Currently, delineation of EC GTV is mainly based on the combined use of CT and ${ }^{18}$ F-FDG-PET/CT. Nevertheless, studies suggest that the correlation between tumor length assessment by CT and pathology is weak with a frequent overestimation of this measurement by CT $[66,67]$. EUS has been proposed for evaluation of the longitudinal extent of the tumor, but results are difficult to translate in the radiotherapy planning process [68]. The excellent soft-tissue contrast of MRI could also substantially help increase the accuracy of tumor delineation in this setting. One study evaluated GTV delineation by 10 observers in six EC patients with MRI compared with ${ }^{18}$ F-FDG-PET/CT [69]. The GTV 
appeared smaller on breath hold T2-weighted and DWI compared to ${ }^{18}$ F-FDG-PET/CT acquired during free-breathing, and the main variation was seen in the cranial caudal direction [69]. Combined DWI and T2-weighted MRI sequences in two tumors of the gastrointestinal junction reduced decreased caudal border variation [69]. However, MRI delineation did not reduce interobserver variability in this study, which could partly be explained by a lack of experience of contouring GTV in EC with this imaging modality. In another study including 42 patients with operated ESCC, DWI was the more accurate modality for the measurement of GTV compared with CT and T2-weighted MRI [66]. The difference in tumor length between CT and pathology was $3.6 \mathrm{~mm}$, while the difference in length between DWI and pathology was as low as $0.5 \mathrm{~mm}$ [66].

Finally, MRI-guided radiotherapy for EC remains under development but seems a promising option for the future. The combination of improved GTV delineation, respiratory gating, and online adaptive planning from daily non-irradiating MRI, could allow for tighter target coverage while sparing the adjacent normal organs [70].

\section{MRI in Assessment of Treatment Response and Prediction of Recurrence}

Several studies have shown improved overall survival with neoadjuvant treatment in patients with localized EC compared with upfront surgery [71-73]. Nevertheless, after neoadjuvant treatment and surgery, about one third of patients with EC show complete pathologic response and are possibly being unnecessarily exposed to the risks of esophagectomy [73]. Moreover, some patients will not respond to neoadjuvant treatment but will be exposed to its side effects. Overall, there is a double challenge of early identification of non-responders to neoadjuvant treatment and precise restaging after chemoradiotherapy to detect residual disease.

Previous studies and meta-analysis have shown that EUS, CT and ${ }^{18}$ F-FDG-PET/CT are not always adequate for the detection of residual disease in EC after neoadjuvant treatment, with poor overall accuracies [34,74-76]. A meta-analysis evaluating pathologic complete response after neoadjuvant treatment with various imaging techniques found pooled sensitivities of 35\% (95\% CI: 16-60), 62\% (95\% CI: 50-73), 1\% (95\% CI: 0-92), and 80\% (95\% CI: 46-95), and pooled specificities of 83\% (95\% CI: 71-91), 73\% (95\% CI: 64-81), 99\% (95\% CI: 81-100), and 83\% (95\% CI: 65-93) for CT, ${ }^{18}$ F-FDG-PET/CT, EUS, and MRI respectively [77]. Indeed, three-dimensional-CT volumetry evolution is not associated with histopathological tumor response [78]. EUS is limited by the difficulty of differentiating residual tumor from inflammation and fibrosis $[79,80]$. Finally, non-specific glucose uptake after inflammation, or the existence of low FDG uptake cancers limits the role of ${ }^{18}$ F-FDG$\mathrm{PET} / \mathrm{CT}$ in treatment response monitoring.

DWI and the derived apparent diffusion coefficient (ADC) can help assess tumoral metabolic activity and have shown promising results for response prediction in EC in various studies [81-85]. Indeed, results suggest that changes observed between baseline diffusion-weighted images and interim diffusion-weighted images (during treatment) are good prognostic and predictive biomarkers. The relative change in ADC during the first two weeks of chemoradiotherapy appears to be the most predictive for the detection of residual cancer, with a sensitivity of $100 \%$ and specificity of $75 \%$ [83]. Moreover, various b values for ADC have been evaluated in the different available studies overtime [86]. One study has suggested promising results for the prediction of treatment response in EC with the use of intravoxel incoherent motion diffusion-weighted images, which can simultaneously obtain diffusion and perfusion information from tissues without administration of a contrast agent [87]. In addition to DWI, dynamic contrast-enhanced-MRI can also be used to predict response to chemoradiotherapy in EC [88,89]. Finally, weekly T2-weighted MRI in 29 patients undergoing neoadjuvant chemoradiotherapy was able to identify volumetric changes with a significant decrease in tumor regression volume overtime [90].

In a recent meta-analysis including seven studies with EC patients treated by chemoradiotherapy, the pooled sensitivity and specificity of DWI for predicting early response to treatment were 93\% (95\% CI: 77-98\%) and 85\% (95\% CI: 72-73) for the $\triangle \mathrm{ADC}$ (difference 
in ADC values before and after chemoradiotherapy) and 75\% (95\% CI: 62-84) and 90\% (95\% CI: 67-97) for the post ADC [91]. Even if included studies were heterogeneous with small sample sizes, these results suggest a role for DWI in the assessment of treatment response for EC.

The ongoing SANO-2 trial (NCT04886635) is currently evaluating the role of active surveillance with ${ }^{18} \mathrm{~F}$-FDG-PET /CT and endoscopic biopsies after neoadjuvant chemoradiotherapy. Similarly, the randomized ESOSTRATE trial (NCT02551458) is comparing active surveillance versus surgery in patients with compete pathological response after chemoradiotherapy. Finally, the ongoing prospective study PRIDE (NCT03474341) is evaluating a multimodal prediction model including DWI and dynamic contrast-enhanced MRI to predict patient's individual probability of complete pathological response after neoadjuvant chemoradiotherapy and identify early non-responders [92].

\section{Discussion and Perspectives}

Recent improvement in technical modalities of MRI has allowed to better assess the morphology of the normal and pathologic esophagus. Available data in EC is still scarce with small sample size studies and heterogeneity regarding clinical setting and MRI sequences and modalities. Nevertheless, currently used techniques for EC management (CT, ${ }^{18} \mathrm{~F}-\mathrm{FDG}-\mathrm{PET} / \mathrm{CT}$ and EUS) show significant limitations, making MRI a promising tool in both initial staging (T-staging and N-staging) and assessment of response to chemoradiotherapy. There is still not enough data to conclude on the potential role of MRI in detection of distant metastasis as well as follow-up.

High field (7 T) MRI of the esophagus, currently only studied ex vivo, demonstrates an excellent sensitivity and specificity for esophageal cancer. Most importantly, it provides a clear image of the tissue layers of the esophageal wall, comparable to that of endosonography or pathology. The clinical use of this imaging modality - currently limited to the brain and the joints-for the workup of EC could allow an accurate noninvasive tumor staging, even distinguishing shallow T1 lesions potentially amenable to endoscopic resection from $\mathrm{T} 1$ lesions with deep submucosal infiltration or T2 lesions requiring surgical resection. In addition, its ability to discriminate fibrosis from neoplastic tissue makes of high-field MRI a promising candidate to better assess tumor response to neoadjuvant therapy.

\section{Conclusions}

In EC, combinations of different diagnostic modalities might be the way to go for optimal individual staging. In a study on 19 patients with resectable EC, PET-MRI demonstrated acceptable accuracy for T-staging compared with EUS and, although not statistically significant, higher accuracy than EUS and ${ }^{18}$ F-FDG-PET/CT for prediction of $\mathrm{N}$-staging [93]. Furthermore, radiomics and the use of various artificial intelligence-based systems using $\mathrm{CT}$ imaging have recently shown promising results in a variety of diseases, including the diagnosis and monitoring of EC [94-96]. It may be assumed that radiomics and artificial intelligence-centered studies in EC will probably consider data from MRI for even higher performance and accuracy.

Author Contributions: Conceptualization, M.B., A.D., P.S.; methodology, M.B.; validation, A.P., A.D., P.S., J.V., R.C., M.B.; formal analysis, A.P.; investigation, A.P.; resources, A.D., P.S.; data curation, A.P.; writing—original draft preparation, A.P.; writing—review and editing, A.P., A.D., P.S., J.V., R.C., M.B.; visualization, A.D.; supervision, M.B. All authors have read and agreed to the published version of the manuscript.

Funding: This research received no external funding.

Conflicts of Interest: The authors declare no conflict of interest. 


\section{References}

1. Arnold, M.; Abnet, C.C.; Neale, R.E.; Vignat, J.; Giovannucci, E.L.; McGlynn, K.A.; Bray, F. Global Burden of 5 Major Types of Gastrointestinal Cancer. Gastroenterology 2020, 159, 335-349. [CrossRef] [PubMed]

2. Kelly, R.J.; Ajani, J.A.; Kuzdzal, J.; Zander, T.; Van Cutsem, E.; Piessen, G.; Mendez, G.; Feliciano, J.; Motoyama, S.; Lièvre, A.; et al. Adjuvant Nivolumab in Resected Esophageal or Gastroesophageal Junction Cancer. N. Engl. J. Med. 2021, 384, 1191-1203. [CrossRef]

3. Janjigian, Y.Y.; Shitara, K.; Moehler, M.; Garrido, M.; Salman, P.; Shen, L.; Wyrwicz, L.; Yamaguchi, K.; Skoczylas, T.; Campos Bragagnoli, A.; et al. First-Line Nivolumab plus Chemotherapy versus Chemotherapy Alone for Advanced Gastric, Gas-troOesophageal Junction, and Oesophageal Adenocarcinoma (CheckMate 649): A Randomised, Open-Label, Phase 3 Trial. Lancet 2021, 398, 27-40. [CrossRef]

4. $\quad$ Sun, J.-M.; Shen, L.; Shah, M.A.; Enzinger, P.; Adenis, A.; Doi, T.; Kojima, T.; Metges, J.-P.; Li, Z.; Kim, S.-B.; et al. Pembrolizumab plus Chemotherapy versus Chemotherapy Alone for First-Line Treatment of Advanced Oesophageal Cancer (KEYNOTE-590): A Randomised, Placebo-Controlled, Phase 3 Study. Lancet 2021, 398, 759-771. [CrossRef]

5. Lordick, F.; Mariette, C.; Haustermans, K.; Obermannová, R.; Arnold, D. ESMO Guidelines Committee Oesophageal Cancer: ESMO Clinical Practice Guidelines for Diagnosis, Treatment and Follow-Up. Ann. Oncol. 2016, 27, v50-v57. [CrossRef] [PubMed]

6. Veziant, J.; Gaillard, M.; Barat, M.; Dohan, A.; Barret, M.; Manceau, G.; Karoui, M.; Bonnet, S.; Fuks, D.; Soyer, P. Imaging of Postoperative Complications Following Ivor-Lewis Esophagectomy. Diagn. Interv. Imaging 2021, 103, 67-78. [CrossRef] [PubMed]

7. Bosset, J.F.; Gignoux, M.; Triboulet, J.P.; Tiret, E.; Mantion, G.; Elias, D.; Lozach, P.; Ollier, J.C.; Pavy, J.J.; Mercier, M.; et al Chemoradiotherapy Followed by Surgery Compared with Surgery Alone in Squamous-Cell Cancer of the Esophagus. N. Engl. J. Med. 1997, 337, 161-167. [CrossRef]

8. Rice, T.W.; Blackstone, E.H.; Rusch, V.W. 7th Edition of the AJCC Cancer Staging Manual: Esophagus and Esophagogastric Junction. Ann. Surg. Oncol. 2010, 17, 1721-1724. [CrossRef] [PubMed]

9. Manabe, T.; Kawamitsu, H.; Higashino, T.; Lee, H.; Fujii, M.; Hoshi, H.; Sugimura, K. Esophageal Magnetic Resonance Fluoroscopy: Optimization of the Sequence. J. Comput. Assist. Tomogr. 2004, 28, 697-703. [CrossRef] [PubMed]

10. Riddell, A.M.; Richardson, C.; Scurr, E.; Brown, G. The Development and Optimization of High Spatial Resolution MRI for Imaging the Oesophagus Using an External Surface Coil. Br. J. Radiol. 2006, 79, 873-879. [CrossRef] [PubMed]

11. Riddell, A.M.; Davies, D.C.; Allum, W.H.; Wotherspoon, A.C.; Richardson, C.; Brown, G. High-Resolution MRI in Evaluation of the Surgical Anatomy of the Esophagus and Posterior Mediastinum. AJR Am. J. Roentgenol. 2007, 188, W37-W43. [CrossRef] [PubMed]

12. Riddell, A.M.; Allum, W.H.; Thompson, J.N.; Wotherspoon, A.C.; Richardson, C.; Brown, G. The Appearances of Oesophageal Carcinoma Demonstrated on High-Resolution, T2-Weighted MRI, with Histopathological Correlation. Eur. Radiol. 2007, 17, 391-399. [CrossRef] [PubMed]

13. Yamada, I.; Miyasaka, N.; Hikishima, K.; Tokairin, Y.; Kawano, T.; Ito, E.; Kobayashi, D.; Eishi, Y.; Okano, H. Ultra-High-Resolution MR Imaging of Esophageal Carcinoma at Ultra-High Field Strength (7.0T) Ex Vivo: Correlation with Histopathologic Findings. Magn. Reason. Imaging 2015, 33, 413-419. [CrossRef] [PubMed]

14. Weijs, T.J.; Goense, L.; van Rossum, P.S.N.; Meijer, G.J.; van Lier, A.L.H.M.W.; Wessels, F.J.; Braat, M.N.G.; Lips, I.M.; Ruurda, J.P.; Cuesta, M.A.; et al. The Peri-Esophageal Connective Tissue Layers and Related Compartments: Visualization by Histology and Magnetic Resonance Imaging. J. Anat. 2017, 230, 262-271. [CrossRef] [PubMed]

15. Kulinna-Cosentini, C.; Schima, W.; Cosentini, E.P. Dynamic MR Imaging of the Gastroesophageal Junction in Healthy Volunteers during Bolus Passage. J. Magn. Reson. Imaging 2007, 25, 749-754. [CrossRef] [PubMed]

16. Pavone, P.; Cardone, G.P.; Cisternino, S.; Di Girolamo, M.; Aytan, E.; Passariello, R. Gadopentetate Dimeglumine-Barium Paste for Opacification of the Esophageal Lumen on MR Images. AJR Am. J. Roentgenol. 1992, 159, 762-764. [CrossRef]

17. Ogawa, Y.; Noda, Y.; Morio, K.; Nishioka, A.; Inomata, T.; Yoshida, S.; Toki, T.; Ogoshi, S. Ferric Ammonium Citrate-Cellulose Paste for Opacification of the Esophageal Lumen on MRI. J. Comput. Assist. Tomogr. 1996, 20, 455-459. [CrossRef]

18. Faletti, R.; Gatti, M.; Di Chio, A.; Fronda, M.; Anselmino, M.; Ferraris, F.; Gaita, F.; Fonio, P. Concentrated Pineapple Juice for Visualisation of the Oesophagus during Magnetic Resonance Angiography before Atrial Fibrillation Radiofrequency Catheter Ablation. Eur. Radiol. Exp. 2018, 2, 39. [CrossRef]

19. Luo, L.-N.; He, L.-J.; Gao, X.-Y.; Huang, X.-X.; Shan, H.-B.; Luo, G.-Y.; Li, Y.; Lin, S.-Y.; Wang, G.-B.; Zhang, R.; et al. Endoscopic Ultrasound for Preoperative Esophageal Squamous Cell Carcinoma: A Meta-Analysis. PLoS ONE 2016, 11, e0158373. [CrossRef]

20. Subasinghe, D.; Samarasekera, D.N. A Study Comparing Endoscopic Ultrasound (EUS) and Computed Tomography (CT) in Staging Oesophageal Cancer and Their Role in Clinical Decision Making. J. Gastrointest. Cancer 2010, 41, 38-42. [CrossRef]

21. Puli, S.-R.; Reddy, J.-B.; Bechtold, M.-L.; Antillon, D.; Ibdah, J.-A.; Antillon, M.-R. Staging Accuracy of Esophageal Cancer by Endoscopic Ultrasound: A Meta-Analysis and Systematic Review. World J. Gastroenterol. 2008, 14, 1479-1490. [CrossRef]

22. Wakelin, S.J.; Deans, C.; Crofts, T.J.; Allan, P.L.; Plevris, J.N.; Paterson-Brown, S. A Comparison of Computerised Tomography, Laparoscopic Ultrasound and Endoscopic Ultrasound in the Preoperative Staging of Oesophago-Gastric Carcinoma. Eur. J. Radiol. 2002, 41, 161-167. [CrossRef]

23. Kelly, S.; Harris, K.M.; Berry, E.; Hutton, J.; Roderick, P.; Cullingworth, J.; Gathercole, L.; Smith, M.A. A Systematic Review of the Staging Performance of Endoscopic Ultrasound in Gastro-Oesophageal Carcinoma. Gut 2001, 49, 534-539. [CrossRef] [PubMed]

24. Quint, L.E.; Bogot, N.R. Staging Esophageal Cancer. Cancer Imaging 2008, 8, S33-S42. [CrossRef] [PubMed] 
25. Rice, T.W. Clinical Staging of Esophageal Carcinoma. CT, EUS, and PET. Chest Surg. Clin. N. Am. 2000, 10, 471-485. [PubMed]

26. van Westreenen, H.L.; Westerterp, M.; Bossuyt, P.M.M.; Pruim, J.; Sloof, G.W.; van Lanschot, J.J.B.; Groen, H.; Plukker, J.T.M. Systematic Review of the Staging Performance of 18F-Fluorodeoxyglucose Positron Emission Tomography in Esophageal Cancer. J. Clin. Oncol. 2004, 22, 3805-3812. [CrossRef]

27. Choi, J.; Kim, S.G.; Kim, J.S.; Jung, H.C.; Song, I.S. Comparison of Endoscopic Ultrasonography (EUS), Positron Emission Tomography (PET), and Computed Tomography (CT) in the Preoperative Locoregional Staging of Resectable Esophageal Cancer. Surg. Endosc. 2010, 24, 1380-1386. [CrossRef] [PubMed]

28. Van Vliet, E.P.M.; Eijkemans, M.J.C.; Poley, J.-W.; Steyerberg, E.W.; Kuipers, E.J.; Siersema, P.D. Staging of Esophageal Carcinoma in a Low-Volume EUS Center Compared with Reported Results from High-Volume Centers. Gastrointest. Endosc. 2006, 63, 938-947. [CrossRef]

29. Yamada, I.; Murata, Y.; Izumi, Y.; Kawano, T.; Endo, M.; Kuroiwa, T.; Shibuya, H. Staging of Esophageal Carcinoma in Vitro with 4.7-T MR Imaging. Radiology 1997, 204, 521-526. [CrossRef]

30. Yamada, I.; Izumi, Y.; Kawano, T.; Yoshino, N.; Tetsumura, A.; Kumagai, J.; Shibuya, H. Esophageal Carcinoma: Evaluation with High-Resolution Three-Dimensional Constructive Interference in Steady State MR Imaging in Vitro. J. Magn. Reason. Imaging 2006, 24, 1326-1332. [CrossRef]

31. Yamada, I.; Hikishima, K.; Miyasaka, N.; Tokairin, Y.; Kawano, T.; Ito, E.; Kobayashi, D.; Eishi, Y.; Okano, H.; Shibuya, H. Diffusion-Tensor MRI and Tractography of the Esophageal Wall Ex Vivo. J. Magn. Reason. Imaging 2014, 40, 567-576. [CrossRef] [PubMed]

32. Yamada, I.; Hikishima, K.; Miyasaka, N.; Kawano, T.; Tokairin, Y.; Ito, E.; Kobayashi, D.; Eishi, Y.; Okano, H. Esophageal Carcinoma: Ex Vivo Evaluation with Diffusion-Tensor MR Imaging and Tractography at 7 T. Radiology 2014, 272, 164-173. [CrossRef]

33. Wei, Y.; Wu, S.; Gao, F.; Sun, T.; Zheng, D.; Ning, P.; Zhao, C.; Li, Z.; Li, X.; Li, L.; et al. Esophageal Carcinoma: Ex Vivo Evaluation by High-Spatial-Resolution T2 -Mapping MRI Compared with Histopathological Findings at 3.0T. J. Magn. Reason. Imaging 2017, 45, 1609-1616. [CrossRef] [PubMed]

34. van Rossum, P.S.N.; Goense, L.; Meziani, J.; Reitsma, J.B.; Siersema, P.D.; Vleggaar, F.P.; van Vulpen, M.; Meijer, G.J.; Ruurda, J.P.; van Hillegersberg, R. Endoscopic Biopsy and EUS for the Detection of Pathologic Complete Response after Neoadjuvant Chemoradiotherapy in Esophageal Cancer: A Systematic Review and Meta-Analysis. Gastrointest. Endosc. 2016, 83, 866-879. [CrossRef]

35. Lee, S.L.; Yadav, P.; Starekova, J.; Christensen, L.; Chandereng, T.; Chappell, R.; Reeder, S.B.; Bassetti, M.F. Diagnostic Performance of MRI for Esophageal Carcinoma: A Systematic Review and Meta-Analysis. Radiology 2021, 299, 583-594. [CrossRef] [PubMed]

36. Zhang, F.; Qu, J.; Zhang, H.; Liu, H.; Qin, J.; Ding, Z.; Li, Y.; Ma, J.; Zhang, Z.; Wang, Z.; et al. Preoperative T Staging of Potentially Resectable Esophageal Cancer: A Comparison between Free-Breathing Radial VIBE and Breath-Hold Cartesian VIBE, with Histopathological Correlation. Transl. Oncol. 2017, 10, 324-331. [CrossRef]

37. Kayani, B.; Zacharakis, E.; Ahmed, K.; Hanna, G.B. Lymph Node Metastases and Prognosis in Oesophageal Carcinoma-A Systematic Review. Eur. J. Surg. Oncol. 2011, 37, 747-753. [CrossRef]

38. Zhang, J.; Hu, W.; Zang, L.; Yao, Y.; Tang, Y.; Qian, Z.; Gao, P.; Wu, X.; Li, S.; Xie, Z.; et al. Clinical Investigation on Application of Water Swallowing to MR Esophagography. Eur. J. Radiol. 2012, 81, 1980-1985. [CrossRef]

39. Tang, Y.-L.; Zhang, X.-M.; Yang, Z.-G.; Huang, Y.-C.; Chen, T.-W.; Chen, Y.-L.; Chen, F.; Zeng, N.-L.; Li, R.; Hu, J. The Blood Oxygenation T2* Values of Resectable Esophageal Squamous Cell Carcinomas as Measured by 3T Magnetic Resonance Imaging: Association with Tumor Stage. Korean J. Radiol. 2017, 18, 674-681. [CrossRef] [PubMed]

40. Wu, L.; Ou, J.; Chen, T.-W.; Li, R.; Zhang, X.-M.; Chen, Y.-L.; Jiang, Y.; Yang, J.-Q.; Cao, J.-M. Tumour Volume of Resectable Oesophageal Squamous Cell Carcinoma Measured with MRI Correlates Well with T Category and Lymphatic Metastasis. Eur. Radiol. 2018, 28, 4757-4765. [CrossRef] [PubMed]

41. Chen, Y.-L.; Li, R.; Chen, T.-W.; Ou, J.; Zhang, X.-M.; Chen, F.; Wu, L.; Jiang, Y.; Laws, M.; Shah, K.; et al. Whole-Tumour Histogram Analysis of Pharmacokinetic Parameters from Dynamic Contrast-Enhanced MRI in Resectable Oesophageal Squamous Cell Carcinoma Can Predict T-Stage and Regional Lymph Node Metastasis. Eur. J. Radiol. 2019, 112, 112-120. [CrossRef]

42. Rice, T.W.; Rusch, V.W.; Ishwaran, H.; Blackstone, E.H. Worldwide Esophageal Cancer Collaboration Cancer of the Esophagus and Esophagogastric Junction: Data-Driven Staging for the Seventh Edition of the American Joint Committee on Cancer/International Union Against Cancer Cancer Staging Manuals. Cancer 2010, 116, 3763-3773. [CrossRef] [PubMed]

43. Lerut, T.E.; de Leyn, P.; Coosemans, W.; Van Raemdonck, D.; Cuypers, P.; Van Cleynenbreughel, B. Advanced Esophageal Carcinoma. World J. Surg. 1994, 18, 379-387. [CrossRef] [PubMed]

44. Waterman, T.A.; Hagen, J.A.; Peters, J.H.; DeMeester, S.R.; Taylor, C.R.; Demeester, T.R. The Prognostic Importance of Immunohistochemically Detected Node Metastases in Resected Esophageal Adenocarcinoma. Ann. Thorac. Surg. 2004, 78, 1161-1169. [CrossRef] [PubMed]

45. Bhamidipati, C.M.; Stukenborg, G.J.; Thomas, C.J.; Lau, C.L.; Kozower, B.D.; Jones, D.R. Pathologic Lymph Node Ratio Is a Predictor of Survival in Esophageal Cancer. Ann. Thorac. Surg. 2012, 94, 1643-1651. [CrossRef]

46. van Vliet, E.P.M.; Heijenbrok-Kal, M.H.; Hunink, M.G.M.; Kuipers, E.J.; Siersema, P.D. Staging Investigations for Oesophageal Cancer: A Meta-Analysis. Br. J. Cancer 2008, 98, 547-557. [CrossRef] [PubMed] 
47. Eloubeidi, M.A.; Wallace, M.B.; Reed, C.E.; Hadzijahic, N.; Lewin, D.N.; Van Velse, A.; Leveen, M.B.; Etemad, B.; Matsuda, K.; Patel, R.S.; et al. The Utility of EUS and EUS-Guided Fine Needle Aspiration in Detecting Celiac Lymph Node Metastasis in Patients with Esophageal Cancer: A Single-Center Experience. Gastrointest. Endosc. 2001, 54, 714-719. [CrossRef]

48. Vazquez-Sequeiros, E.; Norton, I.D.; Clain, J.E.; Wang, K.K.; Affi, A.; Allen, M.; Deschamps, C.; Miller, D.; Salomao, D.; Wiersema, M.J. Impact of EUS-Guided Fine-Needle Aspiration on Lymph Node Staging in Patients with Esophageal Carcinoma. Gastrointest. Endosc. 2001, 53, 751-757. [CrossRef]

49. Quint, L.E.; Glazer, G.M.; Orringer, M.B. Esophageal Imaging by MR and CT: Study of Normal Anatomy and Neoplasms. Radiology 1985, 156, 727-731. [CrossRef]

50. Petrillo, R.; Balzarini, L.; Bidoli, P.; Ceglia, E.; D’Ippolito, G.; Tess, J.D.; Musumeci, R. Esophageal Squamous Cell Carcinoma: MRI Evaluation of Mediastinum. Gastrointest. Radiol. 1990, 15, 275-278. [CrossRef]

51. Takashima, S.; Takeuchi, N.; Shiozaki, H.; Kobayashi, K.; Morimoto, S.; Ikezoe, J.; Tomiyama, N.; Harada, K.; Shogen, K.; Kozuka, T. Carcinoma of the Esophagus: CT vs MR Imaging in Determining Resectability. AJR Am. J. Roentgenol. 1991, 156, 297-302. [CrossRef] [PubMed]

52. Mizowaki, T.; Nishimura, Y.; Shimada, Y.; Nakano, Y.; Imamura, M.; Konishi, J.; Hiraoka, M. Optimal Size Criteria of Malignant Lymph Nodes in the Treatment Planning of Radiotherapy for Esophageal Cancer: Evaluation by Computed Tomography and Magnetic Resonance Imaging. Int. J. Radiat. Oncol. Biol. Phys. 1996, 36, 1091-1098. [CrossRef]

53. Wu, L.-F.; Wang, B.-Z.; Feng, J.-L.; Cheng, W.-R.; Liu, G.-R.; Xu, X.-H.; Zheng, Z.-C. Preoperative TN Staging of Esophageal Cancer: Comparison of Miniprobe Ultrasonography, Spiral CT and MRI. World J. Gastroenterol. 2003, 9, 219-224. [CrossRef] [PubMed]

54. Nishimura, H.; Tanigawa, N.; Hiramatsu, M.; Tatsumi, Y.; Matsuki, M.; Narabayashi, I. Preoperative Esophageal Cancer Staging: Magnetic Resonance Imaging of Lymph Node with Ferumoxtran-10, an Ultrasmall Superparamagnetic Iron Oxide. J. Am. Coll. Surg. 2006, 202, 604-611. [CrossRef] [PubMed]

55. Weissleder, R.; Elizondo, G.; Wittenberg, J.; Lee, A.S.; Josephson, L.; Brady, T.J. Ultrasmall Superparamagnetic Iron Oxide: An Intravenous Contrast Agent for Assessing Lymph Nodes with MR Imaging. Radiology 1990, 175, 494-498. [CrossRef]

56. Zhang, F.; Zhu, L.; Huang, X.; Niu, G.; Chen, X. Differentiation of Reactive and Tumor Metastatic Lymph Nodes with DiffusionWeighted and SPIO-Enhanced MRI. Mol. Imaging Biol. 2013, 15, 40-47. [CrossRef]

57. Pultrum, B.B.; van der Jagt, E.J.; van Westreenen, H.L.; van Dullemen, H.M.; Kappert, P.; Groen, H.; Sietsma, J.; Oudkerk, M.; Plukker, J.T.M.; van Dam, G.M. Detection of Lymph Node Metastases with Ultrasmall Superparamagnetic Iron Oxide (USPIO)Enhanced Magnetic Resonance Imaging in Oesophageal Cancer: A Feasibility Study. Cancer Imaging 2009, 9, 19-28. [CrossRef]

58. Sakurada, A.; Takahara, T.; Kwee, T.C.; Yamashita, T.; Nasu, S.; Horie, T.; Van Cauteren, M.; Imai, Y. Diagnostic Performance of Diffusion-Weighted Magnetic Resonance Imaging in Esophageal Cancer. Eur. Radiol. 2009, 19, 1461-1469. [CrossRef]

59. Shuto, K.; Kono, T.; Shiratori, T.; Akutsu, Y.; Uesato, M.; Mori, M.; Narushima, K.; Imanishi, S.; Nabeya, Y.; Yanagawa, N.; et al Diagnostic Performance of Diffusion-Weighted Magnetic Resonance Imaging in Assessing Lymph Node Metastasis of Esophageal Cancer Compared with PET. Esophagus 2020, 17, 239-249. [CrossRef]

60. Alper, F.; Turkyilmaz, A.; Kurtcan, S.; Aydin, Y.; Onbas, O.; Acemoglu, H.; Eroglu, A. Effectiveness of the STIR Turbo Spin-Echo Sequence MR Imaging in Evaluation of Lymphadenopathy in Esophageal Cancer. Eur. J. Radiol. 2011, 80, 625-628. [CrossRef]

61. Jiang, Y.; Chen, Y.-L.; Chen, T.-W.; Wu, L.; Ou, J.; Li, R.; Zhang, X.-M.; Yang, J.-Q.; Cao, J.-M. Is There Association of Gross Tumor Volume of Adenocarcinoma of Oesophagogastric Junction Measured on Magnetic Resonance Imaging with N Stage? Eur. J. Radiol. 2019, 110, 181-186. [CrossRef]

62. Qu, J.; Shen, C.; Qin, J.; Wang, Z.; Liu, Z.; Guo, J.; Zhang, H.; Gao, P.; Bei, T.; Wang, Y.; et al. The MR Radiomic Signature Can Predict Preoperative Lymph Node Metastasis in Patients with Esophageal Cancer. Eur. Radiol. 2019, 29, 906-914. [CrossRef]

63. Kroese, T.E.; Goense, L.; van Hillegersberg, R.; de Keizer, B.; Mook, S.; Ruurda, J.P.; van Rossum, P.S.N. Detection of Distant Interval Metastases after Neoadjuvant Therapy for Esophageal Cancer with 18F-FDG PET(/CT): A Systematic Review and Meta-Analysis. Dis. Esophagus 2018, 31, doy055. [CrossRef]

64. Gong, J.; Cao, W.; Zhang, Z.; Deng, Y.; Kang, L.; Zhu, P.; Liu, Z.; Zhou, Z. Diagnostic Efficacy of Whole-Body Diffusion-Weighted Imaging in the Detection of Tumour Recurrence and Metastasis by Comparison with 18F-2-Fluoro-2-Deoxy-D-Glucose Positron Emission Tomography or Computed Tomography in Patients with Gastrointestinal Cancer. Gastroenterol. Rep. 2015, 3, 128-135. [CrossRef] [PubMed]

65. Malik, V.; Harmon, M.; Johnston, C.; Fagan, A.J.; Claxton, Z.; Ravi, N.; O’Toole, D.; Muldoon, C.; Keogan, M.; Reynolds, J.V.; et al. Whole Body MRI in the Staging of Esophageal Cancer-A Prospective Comparison with Whole Body 18F-FDG PET-CT. Dig. Surg. 2015, 32, 397-408. [CrossRef]

66. Hou, D.-L.; Shi, G.-F.; Gao, X.-S.; Asaumi, J.; Li, X.-Y.; Liu, H.; Yao, C.; Chang, J.Y. Improved Longitudinal Length Accuracy of Gross Tumor Volume Delineation with Diffusion Weighted Magnetic Resonance Imaging for Esophageal Squamous Cell Carcinoma. Radiat. Oncol. 2013, 8, 169. [CrossRef] [PubMed]

67. Sillah, K.; Williams, L.R.; Laasch, H.-U.; Saleem, A.; Watkins, G.; Pritchard, S.A.; Price, P.M.; West, C.M.; Welch, I.M. Computed Tomography Overestimation of Esophageal Tumor Length: Implications for Radiotherapy Planning. World J. Gastrointest. Oncol. 2010, 2, 197-204. [CrossRef]

68. Konski, A.; Doss, M.; Milestone, B.; Haluszka, O.; Hanlon, A.; Freedman, G.; Adler, L. The Integration of 18-Fluoro-Deoxy-Glucose Positron Emission Tomography and Endoscopic Ultrasound in the Treatment-Planning Process for Esophageal Carcinoma. Int J. Radiat. Oncol. Biol. Phys. 2005, 61, 1123-1128. [CrossRef] 
69. Vollenbrock, S.E.; Nowee, M.E.; Voncken, F.E.M.; Kotte, A.N.T.J.; Goense, L.; van Rossum, P.S.N.; van Lier, A.L.H.M.W.; Heijmink, S.W.; Bartels-Rutten, A.; Wessels, F.J.; et al. Gross Tumor Delineation in Esophageal Cancer on MRI Compared With 18F-FDG-PET/CT. Adv. Radiat. Oncol. 2019, 4, 596-604. [CrossRef]

70. Lee, S.L.; Bassetti, M.; Meijer, G.J.; Mook, S. Review of MR-Guided Radiotherapy for Esophageal Cancer. Front. Oncol. 2021, 11, 628009. [CrossRef]

71. Boonstra, J.J.; Kok, T.C.; Wijnhoven, B.P.; van Heijl, M.; van Berge Henegouwen, M.I.; Ten Kate, F.J.; Siersema, P.D.; Dinjens, W.N.; van Lanschot, J.J.; Tilanus, H.W.; et al. Chemotherapy Followed by Surgery versus Surgery Alone in Patients with Resectable Oesophageal Squamous Cell Carcinoma: Long-Term Results of a Randomized Controlled Trial. BMC Cancer 2011, $11,181$. [CrossRef] [PubMed]

72. Sjoquist, K.M.; Burmeister, B.H.; Smithers, B.M.; Zalcberg, J.R.; Simes, R.J.; Barbour, A.; Gebski, V. Australasian Gastro-Intestinal Trials Group Survival after Neoadjuvant Chemotherapy or Chemoradiotherapy for Resectable Oesophageal Carcinoma: An Updated Meta-Analysis. Lancet Oncol. 2011, 12, 681-692. [CrossRef]

73. van Hagen, P.; Hulshof, M.C.C.M.; van Lanschot, J.J.B.; Steyerberg, E.W.; van Berge Henegouwen, M.I.; Wijnhoven, B.P.L.; Richel, D.J.; Nieuwenhuijzen, G.a.P.; Hospers, G.a.P.; Bonenkamp, J.J.; et al. Preoperative Chemoradiotherapy for Esophageal or Junctional Cancer. N. Engl. J. Med. 2012, 366, 2074-2084. [CrossRef] [PubMed]

74. Heneghan, H.M.; Donohoe, C.; Elliot, J.; Ahmed, Z.; Malik, V.; Ravi, N.; Reynolds, J.V. Can CT-PET and Endoscopic Assessment Post-Neoadjuvant Chemoradiotherapy Predict Residual Disease in Esophageal Cancer? Ann. Surg. 2016, 264, 831-838. [CrossRef]

75. Ngamruengphong, S.; Sharma, V.K.; Nguyen, B.; Das, A. Assessment of Response to Neoadjuvant Therapy in Esophageal Cancer: An Updated Systematic Review of Diagnostic Accuracy of Endoscopic Ultrasonography and Fluorodeoxyglucose Positron Emission Tomography. Dis. Esophagus 2010, 23, 216-231. [CrossRef] [PubMed]

76. Eyck, B.M.; Onstenk, B.D.; Noordman, B.J.; Nieboer, D.; Spaander, M.C.W.; Valkema, R.; Lagarde, S.M.; Wijnhoven, B.P.L.; van Lanschot, J.J.B. Accuracy of Detecting Residual Disease After Neoadjuvant Chemoradiotherapy for Esophageal Cancer: A Systematic Review and Meta-Analysis. Ann. Surg. 2020, 271, 245-256. [CrossRef] [PubMed]

77. de Gouw, D.J.J.M.; Klarenbeek, B.R.; Driessen, M.; Bouwense, S.A.W.; van Workum, F.; Fütterer, J.J.; Rovers, M.M.; Ten Broek, R.P.G.; Rosman, C. Detecting Pathological Complete Response in Esophageal Cancer after Neoadjuvant Therapy Based on Imaging Techniques: A Diagnostic Systematic Review and Meta-Analysis. J. Thorac. Oncol. 2019, 14, 1156-1171. [CrossRef]

78. van Heijl, M.; Phoa, S.S.K.S.; van Berge Henegouwen, M.I.; Omloo, J.M.T.; Mearadji, B.M.; Sloof, G.W.; Bossuyt, P.M.M.; Hulshof, M.C.C.M.; Richel, D.J.; Bergman, J.J.G.H.M.; et al. Accuracy and Reproducibility of 3D-CT Measurements for Early Response Assessment of Chemoradiotherapy in Patients with Oesophageal Cancer. Eur. J. Surg. Oncol. 2011, 37, $1064-1071$. [CrossRef]

79. Zuccaro, G.; Rice, T.W.; Goldblum, J.; Medendorp, S.V.; Becker, M.; Pimentel, R.; Gitlin, L.; Adelstein, D.J. Endoscopic Ultrasound Cannot Determine Suitability for Esophagectomy after Aggressive Chemoradiotherapy for Esophageal Cancer. Am. J. Gastroenterol. 1999, 94, 906-912. [CrossRef] [PubMed]

80. Griffin, J.M.; Reed, C.E.; Denlinger, C.E. Utility of Restaging Endoscopic Ultrasound after Neoadjuvant Therapy for Esophageal Cancer. Ann. Thorac. Surg. 2012, 93, 1855-1859. [CrossRef]

81. Imanishi, S.; Shuto, K.; Aoyagi, T.; Kono, T.; Saito, H.; Matsubara, H. Diffusion-Weighted Magnetic Resonance Imaging for Predicting and Detecting the Early Response to Chemoradiotherapy of Advanced Esophageal Squamous Cell Carcinoma. Dig. Surg. 2013, 30, 240-248. [CrossRef] [PubMed]

82. Aoyagi, T.; Shuto, K.; Okazumi, S.; Shimada, H.; Kazama, T.; Matsubara, H. Apparent Diffusion Coefficient Values Measured by Diffusion-Weighted Imaging Predict Chemoradiotherapeutic Effect for Advanced Esophageal Cancer. Dig. Surg. 2011, 28, 252-257. [CrossRef] [PubMed]

83. van Rossum, P.S.N.; van Lier, A.L.H.M.W.; van Vulpen, M.; Reerink, O.; Lagendijk, J.J.W.; Lin, S.H.; van Hillegersberg, R.; Ruurda, J.P.; Meijer, G.J.; Lips, I.M. Diffusion-Weighted Magnetic Resonance Imaging for the Prediction of Pathologic Response to Neoadjuvant Chemoradiotherapy in Esophageal Cancer. Radiother. Oncol. 2015, 115, 163-170. [CrossRef]

84. Fang, P.; Musall, B.C.; Son, J.B.; Moreno, A.C.; Hobbs, B.P.; Carter, B.W.; Fellman, B.M.; Mawlawi, O.; Ma, J.; Lin, S.H. Multimodal Imaging of Pathologic Response to Chemoradiation in Esophageal Cancer. Int. J. Radiat. Oncol. Biol. Phys. 2018, 102, 996-1001. [CrossRef] [PubMed]

85. Borggreve, A.S.; Heethuis, S.E.; Boekhoff, M.R.; Goense, L.; van Rossum, P.S.N.; Brosens, L.A.A.; van Lier, A.L.H.M.W.; van Hillegersberg, R.; Lagendijk, J.J.W.; Mook, S.; et al. Optimal Timing for Prediction of Pathologic Complete Response to Neoadjuvant Chemoradiotherapy with Diffusion-Weighted MRI in Patients with Esophageal Cancer. Eur. Radiol. 2020, 30, 1896-1907. [CrossRef] [PubMed]

86. Leandri, C.; Soyer, P.; Oudjit, A.; Guillaumot, M.-A.; Chaussade, S.; Dohan, A.; Barret, M. Contribution of Magnetic Resonance Imaging to the Management of Esophageal Diseases: A Systematic Review. Eur. J. Radiol. 2019, 120, 108684. [CrossRef] [PubMed]

87. Li, F.P.; Wang, H.; Hou, J.; Tang, J.; Lu, Q.; Wang, L.L.; Yu, X.P. Utility of Intravoxel Incoherent Motion Diffusion-Weighted Imaging in Predicting Early Response to Concurrent Chemoradiotherapy in Oesophageal Squamous Cell Carcinoma. Clin. Radiol. 2018, 73, 756.e17-756.e26. [CrossRef]

88. Heethuis, S.E.; Goense, L.; van Rossum, P.S.N.; Borggreve, A.S.; Mook, S.; Voncken, F.E.M.; Bartels-Rutten, A.; Aleman, B.M.P.; van Hillegersberg, R.; Ruurda, J.P.; et al. DW-MRI and DCE-MRI Are of Complementary Value in Predicting Pathologic Response to Neoadjuvant Chemoradiotherapy for Esophageal Cancer. Acta Oncol. 2018, 57, 1201-1208. [CrossRef] [PubMed] 
89. Lei, J.; Han, Q.; Zhu, S.; Shi, D.; Dou, S.; Su, Z.; Xu, X. Assessment of Esophageal Carcinoma Undergoing Concurrent Chemoradiotherapy with Quantitative Dynamic Contrast-Enhanced Magnetic Resonance Imaging. Oncol. Lett. 2015, 10, 3607-3612. [CrossRef]

90. Defize, I.L.; Boekhoff, M.R.; Borggreve, A.S.; van Lier, A.L.H.M.W.; Takahashi, N.; Haj Mohammad, N.; Ruurda, J.P.; van Hillegersberg, R.; Mook, S.; Meijer, G.J. Tumor Volume Regression during Neoadjuvant Chemoradiotherapy for Esophageal Cancer: A Prospective Study with Weekly MRI. Acta Oncol. 2020, 59, 753-759. [CrossRef] [PubMed]

91. Cheng, B.; Yu, J. Predictive Value of Diffusion-Weighted MR Imaging in Early Response to Chemoradiotherapy of Esophageal Cancer: A Meta-Analysis. Dis. Esophagus 2019, 32, doy065. [CrossRef] [PubMed]

92. Borggreve, A.S.; Mook, S.; Verheij, M.; Mul, V.E.M.; Bergman, J.J.; Bartels-Rutten, A.; Ter Beek, L.C.; Beets-Tan, R.G.H.; Bennink, R.J.; van Berge Henegouwen, M.I.; et al. Preoperative Image-Guided Identification of Response to Neoadjuvant Chemoradiotherapy in Esophageal Cancer (PRIDE): A Multicenter Observational Study. BMC Cancer 2018, 18, 1006. [CrossRef] [PubMed]

93. Lee, G.; Hoseok, I.; Kim, S.-J.; Jeong, Y.J.; Kim, I.J.; Pak, K.; Park, D.Y.; Kim, G.H. Clinical Implication of PET/MR Imaging in Preoperative Esophageal Cancer Staging: Comparison with PET/CT, Endoscopic Ultrasonography, and CT. J. Nucl. Med. 2014, 55, 1242-1247. [CrossRef] [PubMed]

94. Chidambaram, S.; Sounderajah, V.; Maynard, N.; Markar, S.R. Diagnostic Performance of Artificial Intelligence-Centred Systems in the Diagnosis and Postoperative Surveillance of Upper Gastrointestinal Malignancies Using Computed Tomography Imaging: A Systematic Review and Meta-Analysis of Diagnostic Accuracy. Ann. Surg. Oncol. 2021, 29, 1977-1990. [CrossRef] [PubMed]

95. Chassagnon, G.; Dohan, A. Artificial Intelligence: From Challenges to Clinical Implementation. Diagn. Interv. Imaging 2020, 101, 763-764. [CrossRef] [PubMed]

96. Nakaura, T.; Higaki, T.; Awai, K.; Ikeda, O.; Yamashita, Y. A Primer for Understanding Radiology Articles about Machine Learning and Deep Learning. Diagn. Interv. Imaging 2020, 101, 765-770. [CrossRef] [PubMed] 